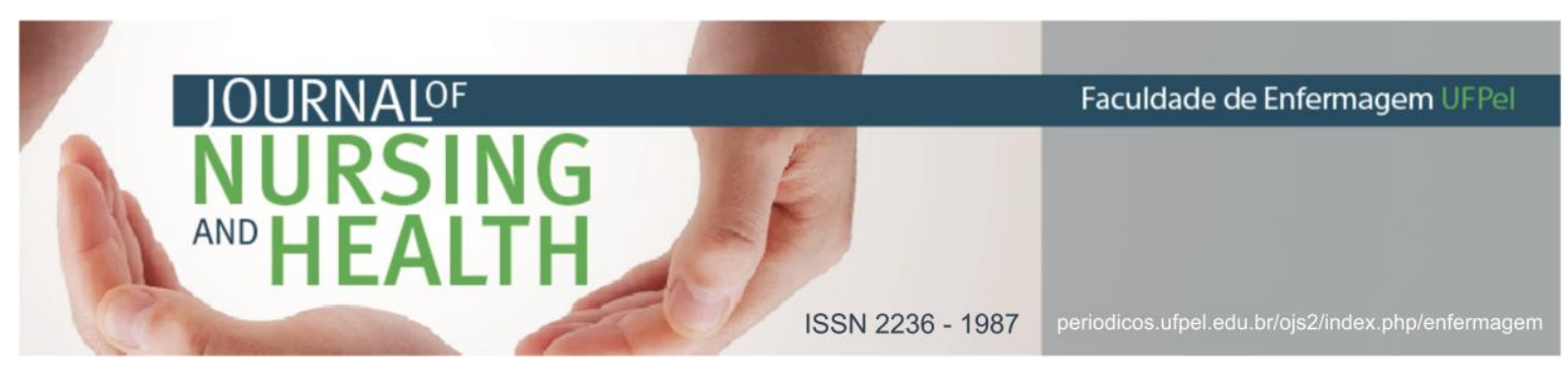

ARTIGO ORIGINAL

\title{
Contribuição da formação em uma universidade privada para inserção dos enfermeiros no mercado de trabalho
}

\section{Contribution of a private university for the insertion of nurses in the labor market
Contribución de la universidad privada para inserción de los enfermeros en el mercado de trabajo

Pafume, Stephanie Morais ${ }^{1}$; da Silva, Érica Caroline ${ }^{2}$; Andrade, Andréia de Carvalho ${ }^{3}$

\begin{abstract}
RESUMO
Objetivo: identificar a percepção do egresso da graduação em Enfermagem sobre as contribuições da universidade privada para inserção no mercado de trabalho. Métodos: pesquisa de campo exploratória, descritiva, de abordagem qualitativa. Os dados foram coletados entre abril e outubro de 2016 por meio de questionário estruturado aplicados a 40 enfermeiros formados em uma universidade privada de São Paulo. Resultados: a análise de conteúdo possibilitou a identificação de três categorias temáticas, sendo: "Sentimento de despreparo para atuação no mercado de trabalho", "Segurança para o primeiro processo seletivo" e "Desenvolvimento de competências para o ser enfermeiro". Considerações finais: identificou-se o sentimento de satisfação da maioria dos egressos na sua formação, de maneira representativa para a inserção no mercado de trabalho e para a vida profissional.
\end{abstract}

Descritores: Educação em enfermagem; Mercado de trabalho; Educação superior.

\begin{abstract}
Objective: to identify the perception of nursing undergraduate egress on the contributions of the private university for insertion in the labor market. Methods: exploratory and descriptive field research, using qualitative approach. The data were collected between April and October 2016 through a structured questionnaire applied to 40 nurses trained at a private university in São Paulo. Results: content analysis made the identification of three thematic categories possible: "Feeling unprepared for action in the job market", "Safety for the first selection process" and "Development of skills for the nurse." Final considerations: the analysis showed that most graduates are satisfied with their training, considering their insertion in the labor market and professional life.

Descriptors: Education, Nursing; Job market; Education, Higher.
\end{abstract}

\section{Resumen}

Objetivo: identificar la percepción del egresado de graduación de la Enfermería sobre las contribuciones de la universidad privada para inserción en el mercado de trabajo. Métodos: investigación de campo exploratoria, descriptiva, de abordaje cualitativo. Los datos fueron

1 Bacharel em Enfermagem. Universidade Cruzeiro do Sul. E-mail: stephanie.mpafume@gmail.com http://orcid.org/0000-0001-7010-9747

2 Bacharel em Enfermagem. Universidade Cruzeiro do Sul. E-mail: erica-carol@uol.com.br https: / / orcid.org/0000-0001-9895-8185

3 Enfermeira. Doutora em Ciências da Saúde. Universidade Cruzeiro do Sul. E-mail: andreiadecarvalho@terra.com.br https: //orcid.org/0000-0002-1105-3023 


\section{JOURNAIOF

recolectados entre abril y octubre de 2016 por medio de un cuestionario estructurado aplicado a 40 enfermeros formados en una universidad privada de São Paulo. Resultados: el análisis de contenido posibilitó la identificación de tres categorías temáticas, siendo: "Sentimiento de falta de preparación para la actuación en el mercado de trabajo", "Seguridad para el primer proceso selectivo" y "Desarrollo de competencias para el ser enfermero". Consideraciones finales: se identificó el sentimiento de satisfacción de la mayoría de los egresados en su formación, de manera representativa para la inserción en el mercado de trabajo y para la vida profesional.

Descriptores: Educación en enfermería; Mercado de trabajo; Educación superior.

\section{INTRODUÇÃO}

Estudos mostram que o perfil do egresso contratado como profissional enfermeiro vem mudando significativamente ao longo das últimas décadas, devido às mudanças nas exigências e necessidades do mercado de trabalho, bem como as transformações econômicas, científicas e tecnológicas que acarretaram mudanças na política educacional. ${ }^{1-2}$

O mercado de trabalho dispõe de um elevado número de profissionais em busca do primeiro emprego, na sua área de formação, gerando competitividade e ofertando às empresas maior quantitativo de candidatos, tornando-as mais seletivas na contratação de seus colaboradores. ${ }^{3}$

O setor de saúde sofre constantes mudanças e avanços no conhecimento, - qual geram novos cenários no mercado de trabalho e que exigem determinadas características dos profissionais de saúde, como o desenvolvimento de competências específicas em nível de conhecimentos, habilidades e atitudes, incluindo o enfermeiro, que deve sempre se atualizar e complementar sua formação acadêmica a fim de acompanhar essas modificações e atuar de modo a satisfazer as necessidades da população assistida. ${ }^{4}$
A partir desses aspectos, os egressos vivenciam um cenário desafiador na transição da academia para o mercado de trabalho, gerando ansiedade e preocupação por terem de assumir as responsabilidades atribuídas ao enfermeiro ao desempenhar esse papel com competência, mesmo enquanto recém-formados, diante de um cenário competitivo e exigente. ${ }^{3}$

Diante dessa realidade, questionou-se as contribuições da Graduação em Enfermagem em uma universidade privada de São Paulo para inserção no mercado de trabalho.

No Brasil, a partir da Lei de Diretrizes e Bases (LDB), o Ministério da Educação (MEC) instituiu as Diretrizes Curriculares Nacionais (DCN) do Curso de Graduação em Enfermagem na resolução do Conselho Nacional de Educação e da Câmara de Educação Superior (CNE/CES) $n^{\circ} 3$, que descreveu como perfil do egresso de Enfermagem como, "enfermeiro, com formação generalista, humanista, crítica e reflexiva. Profissional

qualificado para o exercício de Enfermagem, com base no rigor científico e intelectual e pautado em princípios éticos. Capaz de conhecer e intervir sobre os problemas/situações de saúde-doença mais prevalentes no perfil epidemiológico nacional, com 


\section{JOURNALOF

\section{ISSN 2236 - 1987}

ênfase na sua região de atuação, identificando as dimensões biopsicossociais dos seus determinantes. Capacitado a atuar, com senso de responsabilidade social e compromisso com a cidadania, como promotor da saúde integral do ser humano". 5:01

As DCN ainda definiram que todos os cursos de Enfermagem do Brasil devem possibilitar ao discente, obrigatoriamente, o desenvolvimento de competências gerais para que seja um profissional apto a desenvolver ações de prevenção, promoção, proteção e reabilitação da saúde; Capacitado a tomar decisões, de se comunicar de modo verbal e não verbal além de ter habilidades de escrita e leitura; Liderança na equipe multiprofissional; Administração e gerenciamento dos recursos para o processo de trabalho cuidar, bem como a educação permanente, pois esses profissionais devem ser capazes de aprender continuamente. ${ }^{5}$

No mesmo grau de importância, os egressos de Enfermagem devem possuir competências técnicocientíficas para a área de atuação, ética e competência políticas e socioeducativas contextualizadas que permitam atuarem no mercado de trabalho. ${ }^{5}$

No processo de ensinoaprendizagem, a participação do discente é fundamental, pois para o desenvolvimento de competências específicas e necessárias na formação de um profissional, ele deverá participar de discussões em grupo, treinamentos, grupos de estudos e trabalhos, realização de projetos de extensões, atividades investigativas, dentre outras, desenvolvendo-se a fim de atender às exigências do mercado de trabalho pautado nas competências instituída pelas $\mathrm{DCN}{ }^{6}$

É crescente a adesão e representatividade das Instituições de Ensino Superior (IES) de caráter privado, esse fato deve-se ao número elevado de IES particular quando comparado às públicas e também aos estímulos oferecidos pelo governo federal por meio dos programas estudantis que fornecem crédito educativo e bolsas de estudo. No ano de 2015, 705 IES forneceram o curso de Graduação em Enfermagem, sendo 105 de caráter público, enquanto 601 instituições são privadas que correspondem a $85,24 \%$ dos cursos de Enfermagem oferecidos no país, lançando no mercado de trabalho 29.452 egressos. ${ }^{7}$

Compreende-se que existem vários desafios na formação de um enfermeiro no Brasil, tanto para o desenvolvimento teórico-científico como o prático proposto pelas $\mathrm{DCN}$, porém o mercado exige profissionais capazes de exercerem seu papel como agentes inovadores e transformadores da realidade do cenário de saúde. ${ }^{3-4}$

Diante do exposto, tem-se como objetivo identificar a percepção do egresso de Enfermagem sobre as contribuições da universidade privada para inserção no mercado de trabalho.

\section{MATERIAIS E MÉTODOS}

Trata-se de uma pesquisa de campo, exploratória, descritiva, de abordagem qualitativa. 


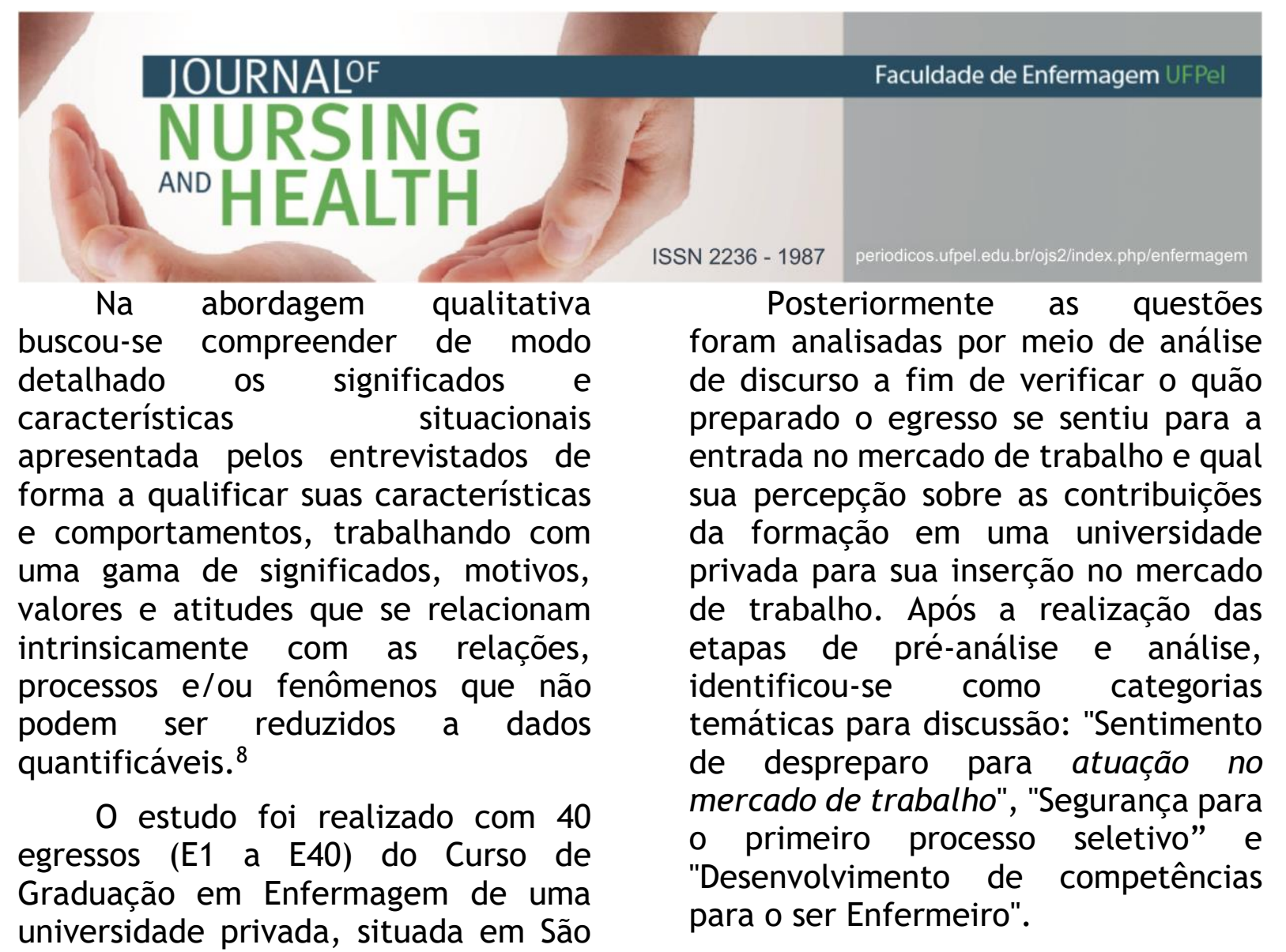
Paulo, representada por egressos de cada ano, a partir da primeira turma (1997) até 2016.

Os participantes da pesquisa foram identificados com auxílio das redes sociais, indicações de egressos e busca ativa em campos de estágios curriculares e extracurriculares. Como critério de inclusão no estudo, considerou-se egressos já inseridos no mercado de trabalho, podendo estar na condição de desemprego.

A coleta de dados foi realizada entre abril e outubro de 2016, por meio da aplicação de um questionário semiestruturado, tendo duas perguntas abertas que indagavam sobre a percepção do egresso ao participar do primeiro processo seletivo e quais as contribuições da formação para a inserção no mercado de trabalho. A coleta de dados ocorreu após autorização do Comitê de Ética e Pesquisa da Universidade (CEP012_2016).

\section{RESULTADOS}

A análise dos resultados possibilitou a discussão referente à percepção dos egressos de Enfermagem sobre as contribuições da universidade privada para inserção no mercado de trabalho.

\section{Sentimento de despreparo para atuação no mercado de trabalho}

Essa categoria foi demarcada por características como inexperiência do recém-formado, imaturidade, insegurança, competitividade no mercado de trabalho e a auto percepção do conhecimento deficiente e emergiu a partir da exposição dos sentimentos relatados por vários egressos e destacados nos depoimentos apresentados a seguir:

[...] conforme a base teórica e o exercício do desenvolvimento do raciocínio teórico cientifico explorado no período de 


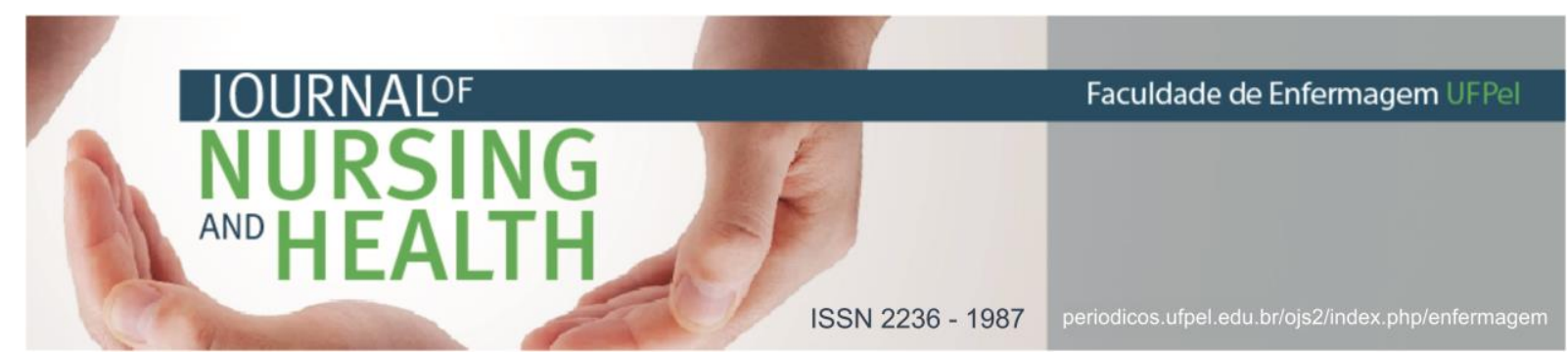

graduação, não me senti segura [...] (EO2).

Todos os meus processos seletivos foram em concurso público e no $2^{\circ}$ concurso federal eu passei em

[...] não me senti preparada pois se exigia muita experiência profissional e o mercado está cada vez mais competitivo [...] (E03).

[...] os conteúdos desenvolvidos em sala de aula foram poucos $e$ insuficientes preparatórios para o mercado de trabalho. Definitivamente a instituição não me preparou para isto (E10).

[...] me sentia insegura, acreditava não estar completamente preparada para realizar as diversas atribuição $e$ responsabilidade de um enfermeiro (E11).

\section{Segurança para o primeiro processo seletivo}

Essa categoria emergiu a partir da exposição dos relatos de egressos apresentados a seguir:

Teoricamente o conhecimento teórico e científico me traziam segurança, porém, a prática me sentia com um déficit até que percebi que o conhecimento norteia a conduta (E01).

Fiquei muito satisfeita com o conteúdo oferecido pela graduação, qualidade dos professores didática. Acredito que o empenho do candidato nos processos seletivos no sentido de revisar o conteúdo da graduação [...] (E04).

$1^{\circ}$ lugar. Acredito que 0 aprendizado teórico e prático contribuiu [...] (E05).

O conteúdo teórico conjunto com a prática (estágio precoce) favorece a formação crítica em tempo de ir atrás de informações em semestre subsequentes [...] (E16).

Me senti preparada, pois já possuía a vivência de estagiária na instituição, conhecendo as rotinas e equipe de enfermagem (E21).

Desenvolvimento de competências para o ser Enfermeiro
Essa categoria emergiu a partir dos depoimentos referente à importância de desenvolver na graduação conhecimentos, habilidades e atitudes específicas, enquanto contribuição para inserção do egresso no mercado de trabalho, como mencionado abaixo:

Muito bom, os conteúdos oferecidos pela universidade foram de abrangência abordando os principais conteúdos [...] (E09).
Minha percepção é que o papel da Universidade dá o embasamento científico para a atuação do enfermeiro no mercado de trabalho (E22).




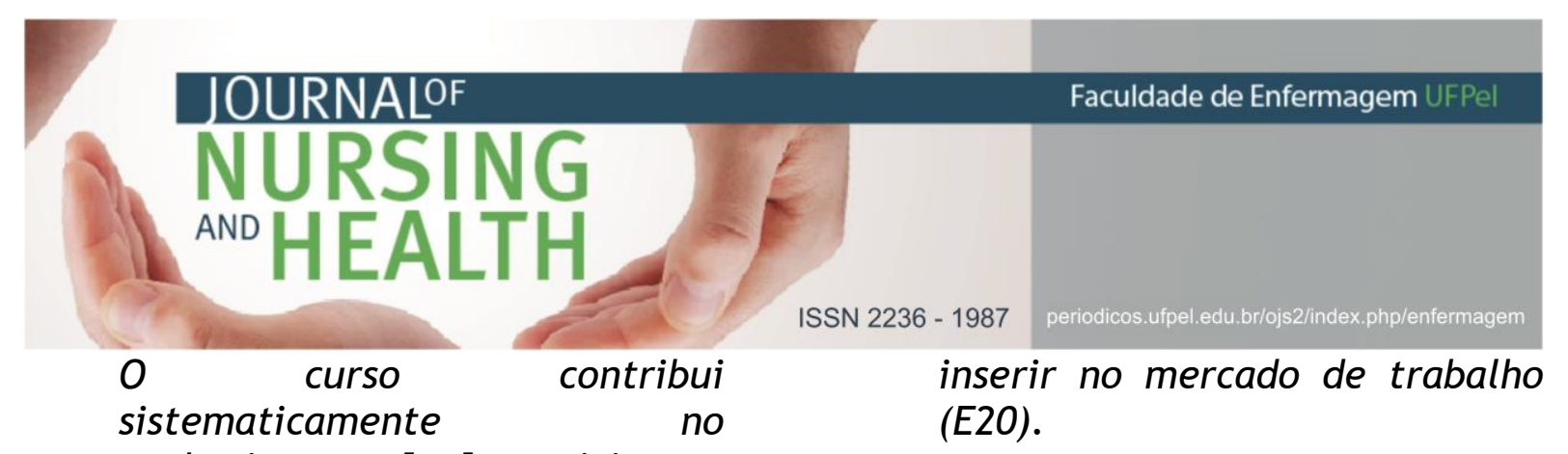

conhecimento [...] participação no processo seletivo $e \quad o$ conhecimento adquirido foi fundamental para finalização do processo com sucesso (E24).

Foi um curso muito bom e com muitas oportunidades de conhecimento e aprendizado [...] (E29).

Achei bom o conteúdo teórico ao longo da graduação. Me senti segura e preparada para realizar os processos seletivos [...] (E36).

Os egressos também referiram que o fator que mais contribuiu para sua inserção no mercado de trabalho foi o de adquirir destrezas em processos específicos de enfermagem.

Diferencial de inicio de práticas clínicas desde os primeiros semestres possibilitando melhor assimilação de conteúdos (E14).

A começar pelo excelente grupo de professores, a universidade focou bastante nas questões práticas. Os estágios iniciam bem precocemente $e$ isso facilita muito a compreensão das disciplinas $[. .$.$] (E18).$

No meu caso o que mais foi válido foram os estágios no decorrer do curso pois não tinha experiência nenhuma em hospital, acredito que os estágios me deram mais segurança para participar do processo seletivo e assim me
0 curso proporcionou o conhecimento para atuar $e$ desenvolver minhas habilidades/destrezas (E21).

Os egressos ainda citaram como fator facilitador para a inserção no mercado de trabalho, as atividades extracurriculares como contribuinte para a formação e o aprimoramento profissional do ser enfermeiro, o que possibilita o desenvolvimento de habilidade e associação da teoria com a prática profissional.

A faculdade contribuiu muito com a grade/estágios desde o início do curso dando segurança e vivencia "profissional" possibilitando a o egresso ao mercado de trabalho com mais segurança. [...] Um dos pontos positivos da faculdade foi $o$ incentivo dos professores a buscar e participar de eventos científicos, monitorias $e$ trabalhos voluntários (E03).

Pontos favoráveis que a universidade me ofereceu, foi por exemplo, a oportunidade de seleção para monitoria das disciplinas [...] oportunidade de Iniciação Científica [...] Os estágios e as práticas clínicas precoces contribuem bastante. [...] (E04).

o desenvolvimento de competências foi mencionado por vários egressos, destacam-se dois discursos que apresentaram os fatores 


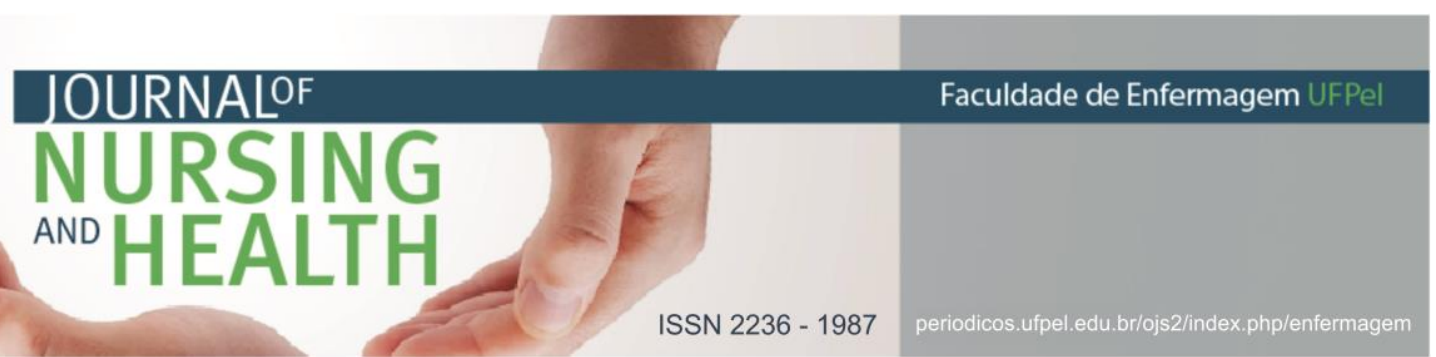

de contribuição para inserção no mercado de trabalho.

Muito produtivo o curso me passou grande conhecimento teórico e prático pois, tinha uma certa dificuldade por não ter realizado o curso técnico em Enfermagem. Percebi que não implicava no meu aprendizado e prática a não formação como técnica. $O$ enfermeiro possui uma visão holística, administra, gerencia, passei a conhecer a profissão mais a fundo [...] (E01).

[...] experiência teórico-prática enriquecedora. Tive professores maravilhosos e que souberam passar seus conhecimentos $e$ experiências [...] (E31).

\section{DISCUSSÃO}

A análise da contribuição do curso de graduação, na formação dos egressos para sua inserção no mercado de trabalho é objetivo de outros estudos, contudo, ainda são insipientes para dar base a uma caracterização do perfil geral dos egressos do curso de enfermagem, uma vez que as instituições brasileiras têm diferentes realidades as quais utilizam para adequar o profissional formado ao mercado de trabalho, local que exige demanda especifica a respeito de sua realidade sociodemográfica, contudo são estudos relevantes que podem trazer ferramentas ou suscitar ideias e adequações para que outras instituições consigam adaptar seus projetos pedagógicos, além de contribuir para a reflexão entre teoria, prática e o mundo acadêmico e

profissional, a fim de formar egressos aptos para facilitar sua inserção no mercado de trabalho. ${ }^{9-11}$

As instituições possuem certa liberdade na criação de seus currículos, mas necessitam abarcar as propostas das DCN, considerando a exigência de uma formação generalista e que atenda as necessidades regionais, porém deve haver também uma preocupação real com o preparo do discente na inserção do mercado de trabalho atual. Durante o processo de formação, o discente deverá vivenciar diferentes cenários de preparo profissional, o qual possibilitará maior visão dos processos de trabalho, além de possibilitar o desenvolvimento de competências necessárias para atuação em variadas áreas da saúde nas quais o Enfermeiro pode atuar, sendo ainda uma oportunidade para definir a especialização a ser escolhida pelo egresso. ${ }^{6,9,11-12}$

A perspectiva do egresso deve ser analisada como fator decisivo para avaliar a qualidade da formação, uma vez que é ele quem confronta o conhecimento e desenvolvimento teórico-científico, técnico, ético e humano adquirido com as expectativas do mercado de trabalho. Esse feedback poderá promover um replanejamento do projeto pedagógico, sendo um fator decisivo para o sucesso da formação em algumas instituições, enquanto que para os egressos com defasagem de conhecimento, a busca por especialização e adoção de uma postura ativa é fundamental para o desenvolvimento de competências com defasagens. ${ }^{11,13}$ 


\section{NURSING \\ AND \\ HEALTH}

Os depoimentos dos egressos apontam para a falta de experiência, seguida pelo mercado de trabalho saturado e falta de especialização, mas também faz menção à importância do interesse individual do discente em desenvolver as competências necessárias, pois este fator aliado a uma boa estrutura da instituição, corpo docente preparado e um projeto pedagógico adequado, podem facilitar a inserção do egresso no mercado de trabalho. Outro fator levantado pelos egressos desse trabalho foi a insegurança que gerava por vezes um sentimento de despreparo para 0 desempenho de suas funções, contudo esta tem sido uma vivência enfrentada por diversos egressos de outras instituições. ${ }^{4,14-15}$

0 desafio de formar enfermeiros preparados para a realidade no exercício profissional é também observado em outros países e o Conselho Internacional de Enfermagem (CIE), bem como a Organização Mundial da Saúde reconhecem essa dificuldade e alertam sobre a necessidade de investimentos, melhorias tanto da estrutura física, quanto dos recursos humanos envolvidos no processo com a participação ativa de gestores públicos na área de saúde e educação, servidores técnico-administrativos, docentes, discentes, entidades de classe e usuários possibilitando a maximização da aprendizagem dos discentes a fim de entregar um profissional com um currículo pautado nas necessidades dos serviços, dos profissionais e da sociedade. ${ }^{16-17}$
ISSN $2236-1987$

Em contrapartida, entende-se que a formação abarca também responsabilidades do aluno com seu processo de aprendizado, diminuindo a centralização do conhecimento adquirido apenas pelo docente, contribuindo para uma maior autonomia do graduando no processo ensino-aprendizagem, tornando 0 docente apenas um mediador deste processo sendo necessária então a participação ativa do aluno.

Deve-se evidenciar a relevância e impacto positivo que existe na participação dos atores envolvidos no processo de formação e atuação dos enfermeiros na avaliação do currículo, o qual possibilita o levantamento de pontos a serem melhorados para um realinhamento contínuo na formação profissional, consequentemente, a melhoria concreta na qualidade do currículo do Curso de Graduação em Enfermagem, condizente com a necessidade da população refletida na necessidade do mercado. ${ }^{17}$

0 fato de serem jovens também constituiu um obstáculo enfrentado pelos egressos no início de suas atividades profissionais, denotando uma necessidade de busca de conhecimento para atender as expectativas do mercado de trabalho, o egresso deve demonstrar autonomia e segurança para ser inserido, sendo que a mudança no perfil exigido passa por um momento de incerteza para o jovem trabalhador, por não possuir experiência e ter que competir com profissionais já experientes e provavelmente se encontrará em desvantagem devido esse aspecto. 3,18 
ISSN 2236 - 1987

assistencial, de diferentes modos e com sucesso. ${ }^{13}$

0 ensino baseado em competências é uma estratégia em crescimento que tem se mostrado efetiva, uma vez que entrega ao mercado profissionais eficientes e de qualidade, o qual são capazes de se adaptar às constantes mudanças e aos desafios impostos pelo mercado de trabalho. Propõem-se 0 desenvolvimento das competências gerais do enfermeiro voltados a atenção à saúde, tomada de decisão, liderança, educação permanente, comunicação, administração e gerenciamento, itens que devem ser explorados e aprofundados na formação para garantir a manutenção e 0 aperfeiçoamento desses profissionais no mercado de trabalho do mundo globalizado. ${ }^{20-21}$

Destaca-se, por exemplo, a competência de liderança, em que alunos com aprendizado de liderança consolidado conseguem concluir o processo de transição alunoenfermeiro, apresentando maiores chances de sucesso e ascensão profissional. $^{21}$

O conhecimento é um dos pilares que mais sustenta as competências. É o produto de experiências, de aprendizagem, de busca de informações e de elaborações mentais aplicados de forma objetiva e eficaz, sendo base para a formação acadêmica efetiva, além de ser um fator que dá suporte aos egressos na inserção no mercado de trabalho, pois mesmo sem desenvolvimento completo de habilidades específicas, confere 


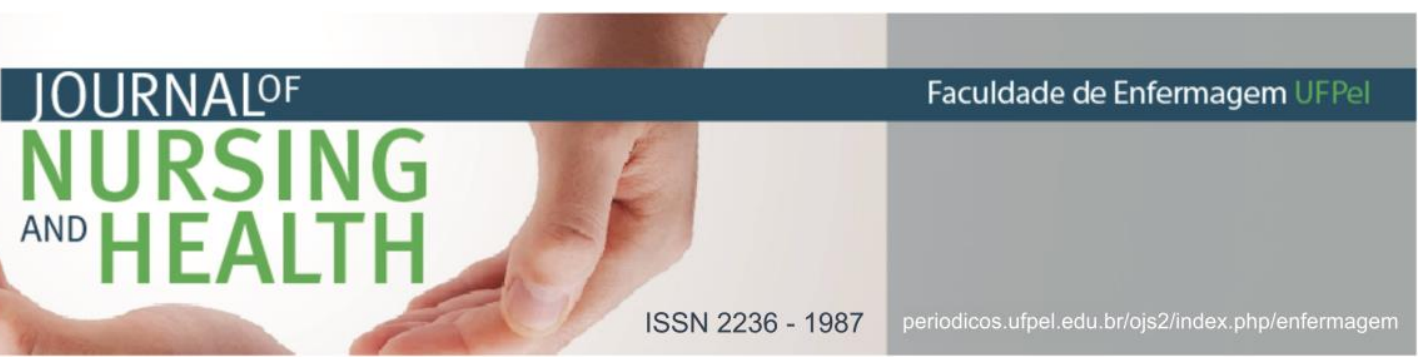

segurança e promove atitudes que primam por aprimoramento. 9,17

0 desenvolvimento de habilidades foi um dos pontos fortes levantados por egressos de outros estudos em instituições públicas e privadas, em que foram apontadas como parte significativa na formação, a oportunidade em vivenciar a prática profissional durante o período regular com inicio precoce, antecipando as experiências com estágios curriculares. Também, outros momentos em atividades extracurriculares, como monitorias, fazendo com que os discentes entrem em contato com os diversos cenários de atuação do enfermeiro poderá ser um facilitador para inserção no mercado de trabalho e facilitador na adaptação do egresso na prática profissional, pois desenvolve maior segurança na profissão. ${ }^{9,14-15}$

A monitoria compreende um serviço de apoio pedagógico que possibilita aos acadêmicos a oportunidade de aprofundar conhecimentos e solucionar eventuais dificuldades relacionadas à disciplina trabalhada. Nesse sentido, permite a ocorrência de uma melhor correlação entre teoria e prática, possibilitando que durante o processo de ensino e aprendizagem, seja criado um espaço onde o aluno possa interrogar, praticar e revisar conteúdos trabalhados em sala de aula com menor grau de receio, favorecendo assim um maior nível de confiança quanto a realização dos procedimentos e desenvolvimento de competências especificas. ${ }^{22}$

As atitudes se referem a comportamentos relacionados com aplicação de princípios e valores e são resultados de ações conscientes, é um dos pilares relacionados ao desenvolvimento de competências, sendo que o enfermeiro deve ser capaz de pensar criticamente, de analisar os problemas e de procurar soluções. ${ }^{22}$

A assistência de enfermagem no Brasil exige do profissional Enfermeiro um líder capaz de atuar na supervisão de auxiliares e técnicos de enfermagem, sendo que essa competência deve ser inicialmente desenvolvida na graduação de modo transversal e fortalecido seu desenvolvimento conforme as experiências na prática profissional, sobretudo atuar como educador sendo capaz não só de promover educação permanente, bem como realizar ações de educação em saúde que sejam efetivas e visem o autocuidado e a promoção a saúde da população, exigindo do egresso logo de inicio uma postura diferenciada com desenvolvimento de habilidades e atitudes, respaldados em conhecimentos que devem ser muito bem enraizados durante sua formação para garantir que as competências sejam melhoradas ao longo de sua atuação. ${ }^{11,23}$

0 docente tem importante participação nesse processo, pois tem a responsabilidade de avaliar a aprendizagem, incluindo procedimentos que possibilite a análise dos progressos dos discentes quanto ao desenvolvimento dos conhecimentos, habilidades e atitudes. 0 docente é por vezes citado como facilitador, já que é atribuído a ele o papel de guiar quais as competências são necessárias frente 


\section{JOURNALOF \\ NURSING \\ ANO HEALTH \\ ISSN 2236 - 1987}

aos diversos cenários, também citado por alguns egressos neste estudo. ${ }^{24}$

Um bom docente é, portanto, aquele que permite participação ativa e corrobora com seu crescimento e desenvolvimento, motivando e incentivando os estudantes na busca de construção do conhecimento, desenvolvendo assim suas habilidades e atitudes, um processo desenvolvido diariamente, onde a aplicação destes se expressa no saber, no saber fazer e no saber ser. ${ }^{22,24}$

Deste modo, o trabalho possibilitou explanar o fato que competências específicas são aspectos primordial para o exercício profissional do ser enfermeiro. Assim, de acordo com os depoimentos, a formação possibilitou o desenvolvimento de competências, em nível de conhecimento, habilidades e atitudes que corroboraram para o preparo do enfermeiro e consequentemente, para sua inserção no mercado de trabalho.

\section{CONSIDERAÇÕES FINAIS}

A análise deste estudo possibilitou identificar as contribuições do curso de Graduação em Enfermagem e a percepção desses egressos sobre a importância de sua formação para a inserção no mercado de trabalho por meio da discussão de quatro categorias temáticas: "Sentimento de despreparo para atuação no mercado de trabalho", "Segurança para o primeiro processo seletivo" e "Desenvolvimento de competências para o ser enfermeiro".

Identificou-se a partir da análise dos discursos, uma satisfação na formação por parte dos egressos, colocando em evidência o fato de o curso ter contribuído de forma representativa para sua inserção no mercado de trabalho e consequentemente para sua vida profissional, sendo essa contribuição direta ou indireta, visto que alguns sentiram ainda na graduação necessidade de aperfeiçoamento para a inserção no mercado de trabalho e buscaram por isso, sendo este um fator a ser destacado.

Os egressos apontaram que 0 conhecimento é primordial, contudo os aspectos atitudinais desenvolvidos durante a graduação é também um fator de grande influência para possibilitar a inserção no mercado de trabalho. Esse fator é cada vez mais exigido para o preparo de profissionais aptos a atenderem as expectativas, detentor de uma série de competências essenciais para ser enfermeiro.

Ressaltaram ainda que, o início precoce das práticas clínicas na IES já no terceiro semestre de graduação é um diferencial na formação de Enfermagem, sendo indispensável à vivência em ambientes hospitalares e não hospitalares, podendo servir de modelo a ser seguido em outras instituições por ser um facilitador no processo de formação profissional. A formação ainda possibilitou a oportunidade de desenvolver habilidades práticas nos núcleos clínicos, além de possibilitar ao aluno participar de monitorias e/ou grupos de atendimento, que na visão do egresso foram benéficas por corroborar com 0 desenvolvimento de 


\section{NURSING \\ AND}

ISSN 2236 - 1987

competências para a formação do enfermeiro.

Apesar deste estudo ter como limitação, a análise da percepção de um grupo específico de egressos e, por se tratar de uma amostra não probabilística que faziam parte de uma instituição particular, cujo projeto curricular diferenciado pode não refletir a realidade de egressos de outras instituições, é evidente que diversas ferramentas podem e devem ser utilizadas pelas IES com a finalidade de desenvolver as competências específicas para que o aluno realmente se torne competente ao exercício profissional e seja inserido no mercado trabalho como enfermeiro.

\section{REFERÊNCIAS}

1. Higa EFR, Gomes R, Carvalho MHR, Guimarães APC, Taipeiro EF, Hafner $M L M B$, et al. Percepção do egresso de enfermagem sobre a contribuição do curso para o exercício do cuidado. Texto \& contexto enferm. [Internet] 2013 jan/mar[acesso em 2018 jul 20];22(1):97-105. Disponível em: http://www.scielo.br/pdf/tce/v22n1/ pt_12.pdf

2. Manarin AP, Botoleto CB, FerreiraSae MCS. Perspectivas do egresso de enfermagem frente ao mercado de trabalho. Ensaios cienc, cienc biol agrar saúde. [Internet] 2009[acesso em 2018 jul 20];8(1):93-105. Disponível em:

http: / / www.redalyc.org/pdf/260/260 12800009.pdf

3. Jesus BH, Gomes DC, Spilleri LBB, Prado ML, Canever BP. Inserção no mercado de trabalho: trajetória de egressos de um curso de graduação em enfermagem. Esc Anna Nery (Online). [Internet] $2013 \mathrm{abr} /$ jun[acesso em 2018 jul 20];17(2):336-45. Disponível em:

http://www.scielo.br/pdf/ean/v17n2 /v17n2a19.pdf

4. Ortega MCB, Cecagno D, Lior MAS, Siqueira $\mathrm{HCH}$, Montesinos MJL, Soler LM. Formação acadêmica do profissional de enfermagem e sua adequação as atividades de trabalho. Rev latinoam enferm (Online). [Internet] 2015[acesso em 2018 jul 20];23(3):404-10. Disponível em: http: / /www.scielo.br/pdf/rlae/v23n3 /pt_0104-1169-rlae-23-03-00404.pdf

5. Brasil. Ministério da Educação. Conselho Nacional de Educação. Câmara de Educação Superior. Resolução CNE/CES n. 3, de 7 de novembro de 2001. Institui Diretrizes Curriculares Nacionais do curso de graduação em Enfermagem. Diário Oficial da União. 9 nov 2001;Seção $1: 37$.

6. Santos SSC. Perfil de egresso de curso de enfermagem nas Diretrizes Curriculares Nacionais: uma aproximação. Rev bras enferm. [Internet] $2006 \mathrm{mar} / \mathrm{abr}$ [acesso em 2018 jul 20];59(2):217-21. Disponível em:

http://www.scielo.br/pdf/reben/v59 n2/a18.pdf

7. Instituto Nacional de Estudos e Pesquisas Educacionais Anísio Teixeira. Sinopse Estatística da Educação Superior 2015 [Internet]. Brasília, 2016 [acesso em 2017 outubro 03]. Disponível em: http://portal.inep.gov.br/web/guest/ 


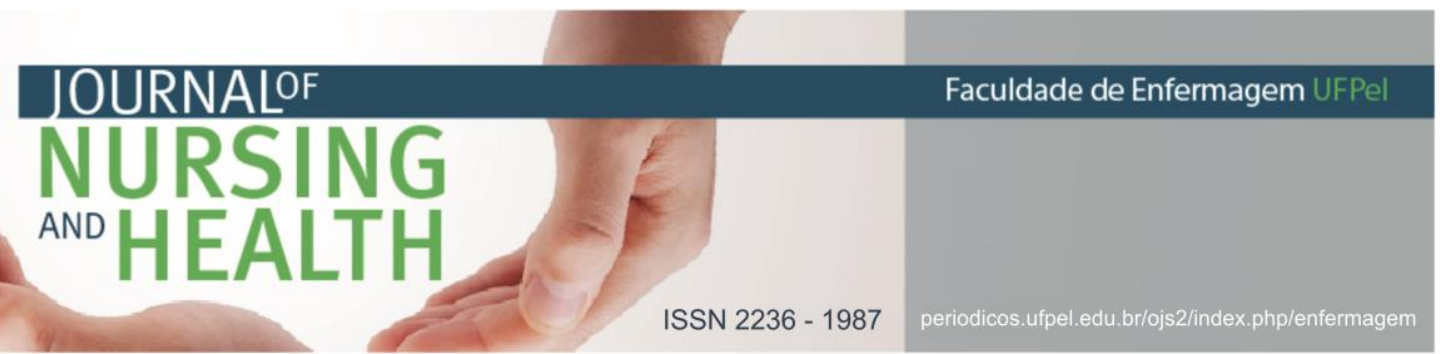

sinopses-estatisticas-da-educacaosuperior

8. Lakatos EM, Marconi MA. Fundamentos de metodologia científica. $8^{\mathrm{a}}$ ed. São Paulo: Atlas; 2017.

9. Canever BP, Gomes DC, Jesus BH, Spiullere LB, Prado ML, Backes VMS. Processo de formação e inserção no mercado de trabalho: uma visão dos egressos de enfermagem. Rev gaúch enferm. [Internet] 2014[acesso em 2018 jul 20];35(1):97-3. Disponível em: http://seer.ufrgs.br/index.php/Revist aGauchadeEnfermagem/article/view/ $43279 / 28939$

10. Francisco AM, Costa MCG, Hamamoto CG, Hafner MLMB. Avaliação da formação de enfermeiros: o reflexo dos métodos de ensinoaprendizagem e pressupostos curriculares na prática profissional. Avaliação (Campinas). [Internet] 2016[acesso em 2018 jul 20];21(2):479$502 . \quad$ Disponível em: http: / /www.scielo.br/pdf/aval/v21n2 /1982-5765-aval-21-02-00479.pdf

11. Rodrigues RM, Conterno SFR, Guedes GC. Formação na graduação em enfermagem e impacto na atuação profissional na perspectiva de egressos. Interfaces da educ. [Internet] 2015[acesso em 2018 jul 20];6(17):26-43. Disponível em: https://periodicosonline.uems.br/ind ex.php/interfaces/article/view/744

12. Makuch DMV, Zagonel IPS. A perspectiva do mundo do trabalho nas proposições curriculares para formação do enfermeiro. Rev inter educ saúde. [Internet] 2017[acesso em 2018 jul 20];(1):13-22. Disponível:

https://www5.bahiana.edu.br/index. php/educacao/article/download/1319 1987

13. Nunes NJS, Carvalho LA, Amestoy SC, Thofehrn MB, Hypolito AM. Educação Baseada em competências na enfermagem. J nurs health. [Internet] 2016[acesso em 2018 jul 20];6(3):447$63 . \quad$ Disponível em: https: / /periodicos.ufpel.edu.br/ojs2/ index.php/enfermagem/article/view/ $6055 / 6922$

14. Cambiriba TFC, Ferronato AF, Fontes KB. Percepções de egressos de enfermagem frente a inserção no mercado de trabalho. Arq cienc saude UNIPAR. [Internet] 2014[acesso em 2018 jul 20];18(1):27-32. Disponível em:

http://revistas.unipar.br/index.php/s aude/article/view/5155/2981

15. Püschel VAA, Costa D, Reis PP, Oliveira LB, Carbogim FC. $O$ enfermeiro no mercado de trabalho: inserção, competências e habilidades. Rev bras enferm. [Internet] 2017[acesso em 2018 jul 20];70(6):1288-95. Disponível em: http:/ / www.scielo.br/pdf/reben/v70 n6/pt_0034-7167-reben-70-061220.pdf

16. Trevisan DD, Testi CV, Carmona EV, Silva EM. Formação acadêmica e a prática profissional de Enfermagem: interfaces para reflexão. Rev baiana de saude publica. [Internet] 2014[acesso em 2018 jul 20];38(1):155-62. Disponível em: http://rbsp.sesab.ba.gov.br/index.ph $\mathrm{p} / \mathrm{rbsp} /$ article/view/737/1162

17. Meira MDD, Kurcgant $P$. Educação em enfermagem: avaliação da 


\section{NURSING \\ AND \\ HEALTH}

formação por egressos, empregadores e docentes. Rev bras enferm. [Internet] 2016[acesso em 2018 ju 20];69(1):16-22. Disponível em: http:/ / www.scielo.br/pdf/reben/v69 n1/0034-7167-reben-69-01-0016.pdf

18. Costa TV, Guariente MHDM. Enfermeiros egressos do currículo integrado: inserção e atuação profissional. Rev enferm UFPE on line. [Internet] 2014[acesso em 2018 jul 20];11(1):77-85. Disponível em: http://pesquisa.bvsalud.org/cvsp/res ource/pt/bde-30274

19. Cunha AS, Cavalcanti FR. Recrutamento e seleção de pessoal: análise comparativa entre a iniciativa privada e a pública. Revista espaço acadêmico. [Internet] 2012[acesso em 2018 jul 20] abr;11(131):76-80. Disponível em: http://periodicos.uem.br/ojs/index.p $\mathrm{hp} /$ EspacoAcademico/article/view/14 568/8984

20. Chalita CDO, Silvino ZR, Christovam $B P$, Vidigal PD. Revisão integrativa sobre a formação do enfermeiro baseada em competências. Rev baiana de saude publica. [Internet] 2016[acesso em 2018 jul 20];40(1):9$23 . \quad$ Disponível em: http://rbsp.sesab.ba.gov.br/index.ph $\mathrm{p} / \mathrm{rbsp} /$ article/view/660/1870

21. Neves VR, Sanna MC. Conceitos e práticas de ensino e exercício de liderança em Enfermagem. Rev bras enferm. [Internet] 2016[acesso em 2018 jul 20];69(4):733-40. Disponível em:

http://www.scielo.br/pdf/reben/v69 n4/0034-7167-reben-69-04-0733.pdf
ISSN 2236 - 1987

22. Reibnitz KS, Prado NL. Inovação e educação em enfermagem. Florianópolis: Cidade Futura; 2006.

23. Amestoy SC, Trindade LL, Silva GTR, Santos BP, Reis VRSS, Ferreira VB. Liderança na enfermagem: do ensino ao exercício no ambiente hospitalar. Esc Anna Nery. [Internet] 2017[acesso em 2018 jul 20];21(4):1-7. Disponível em:

http://www.scielo.br/pdf/ean/v21n4 /pt 1414-8145-ean-2177-9465-EAN2016-0276.pdf

24. Freitas MAO, Cunha ICKO, Batista SHSS, Rossit RAS. Docência em Saúde: percepções de egressos de um curso de especialização em enfermagem. Interface (Botucatu, Online). [Internet] 2016[acesso 2018 jul 20];20(57):427-36. Disponível em: http://www.scielo.br/pdf/icse/v20n5 7/1807-5762-icse-1807576220150391.pdf

Data de submissão: 12/08/2017

Data de aceite: $27 / 06 / 18$

Data de publicação: 03/08/2018 